\title{
DIE HUIDIGE STAND VAN DIE BELYDENIS IN DIE GEREFORMEERDE KERKEN IN NEDERLAND
}

AS volledig op alle leerstellige, kerkregtelike en liturgiese besluite, van die Sinodes van Sneek 1969, Dordrecht 1971 en Haarlem 1973, ingegaan moet word sou dit 'n lywige boekdeel kan vul. Derhalwe is gekonsentreer op enkele sake wat die ontwikkelingsgang in die G.K.N. gedurende die laaste jare t.o.v. die belydenis die beste weerspieël.

\section{Besware en versoeke op die Sinode van Sneek en Dordrecht}

Die Sinode van Sneek 1969/70 het te doen gekry met 'n stortvloed van besware en versoeke rakende uitsprake van professore Kuitert, Baarda, Hartvelt en Augustyn, oor Skrif en Belydenis. Daar word by die Sinode aangedring om die opvatting byvoorbeeld van Kuitert oor die historisiteit van die sondeval, die historisiteit van Adam en Eva, as strydig met die Belydenis af te wys. Die beskouing van Baarda dat die Evangelies-histories onbetroubaar is, moet veroordeel word, terwyl Augustyn se minagting vir die Belydenis-skrifte nie langer geduld moet word nie.

Daar is geëis dat die Sinode ,uitspreekt dat het ondertekeningsformulier dient te worden gehandhaafd". Alle ampsdraers moet daaraan herinner word dat die belydenis nog steeds akkoord van kerklike gemeenskap is en dat hulle daaraan gebonde is.

Die Agenda van Dordrecht 1971/72 word deur dieselfde sake oorheers. Rapporte oor verskillende aspekte van die belydenis on belydenishandhawing, voortvloeiende uit die besware wat op die Sinode van Sneek gedien het, was ter tafel. Die probleme rondom die belydenisgesag is intussen vererger deur die verskyning van die proefskrif van dr. H. Wiersinga waarin hy die versoening deur voldoening verwerp. Verskillende kerkrade en persone versoek dat Wiersinga se beskouinge veroordeel word en dat die belydenis daadwerklik gehandhaaf word. Daar word ook al hoe sterker aangedring by die Sinode om toe te sien dat die professore aan die V.U. hulle by die opleiding van aanstaande predikante aan die belydenis moet hou.

Hoewel die besware en versoeke op die oog af 'n teken kan wees van besorgdheid oor die handhawing van die belydenis inderdaad word ook daarna verwys as bewys van die G.K.N. se belydenistrou - moet mens dieper as die oppervlakte kyk.

Reeds uit die toedrag van sake - soos hierbo geskets - moet afgelei word dat (teen 1969) die stand van die belydenis in die G.K.N. baie wankelrig was. Die fondament waarop die kerkverband gebou is, was besig om te verkrummel onder die aanslag veral van ampsdraers en wetenskaplikes en van verskillende kante is getrag om die proses van aftakeling te stuit.

Hoe wankel die stand van die Belydenis toe reeds was wat blyk veral uit die feit dat die Sinode oorstroom is met besware en selfs versoeke om uitsprake aangaande wat met die Belydenis in ooreen- 
stemming is al dan nie. Die plaaslike kerk en mindere vergadering het nie die moed gehad om te doen wat voor die handliggend hulle taak was nie. Die onsekerheid oor wat die belydenis en die gesag daarvan is spreek uit die huiwering en selfs weiering van kerkrade en mindere vergaderings om plaaslik teen ampsdraers op te tree. Kuitert het toe al talle predikante en ouderlinge sowel as lidmate, as openlike medestanders gehad wat hulle nuwe opvattinge nie onder tafels en stoele weggesteek het nie. Dink maar aan Delleman, Schuurman, Rothuizen, Baarda en soveel ander wat in geskrifte openlik die nuwe teologie bygeval het. In plaas daarvan dat ooreenkomstig die K.O. gehandel is met die predikante ter handhawing van die belydenis, is magtelose besware en versoeke tot die sinode gerig. Nie een van die besware teen Kuitert bv. het by wyse van appèl voor die Sinode gekom nie.

Die Agenda van die Sinodes van Sneek, Dordrecht en Haarlem - en ook vroeëre Sinodes - toon duidelik dat ' $n$ krisis rondom die belydenis en die gesag daarvan ontstaan het. Die kerke het die sekerheid kwytgeraak en het - seker onbewus - by die valse nederigheid van die nuwe teologie ingeval wat nie in hovaardigheid wil beweer dat hulle alle wysheid in pag het nie, maar opnuut, deur te luister na ander en deur dialoog, tot die waarheid wil deurdring. Daarmee is tegelyk 'n grondbeginsel van die Geref. Kerkreg soos weergegee in die belydenis naamlik dat Christus sy kerk regeer deur mensediens ook in meerdere vergaderinge, losgelaat. Die Sinode het sy regeermag ingeruil vir die dialoog; 'n gesprek moet gevoer word ter bevordering van eenheid i.p.v. vervreemding en skeuringe te veroorsaak deur die eensydige, hovaardige, handhawing van die belydenis wat ook maar mensewerk, vrug van sekere omstandighede en tye is. Die belydenisskrifte is deur die optrede twyfelagtig gestel - daar moet weer na die waarheid gesoek word.

\section{Die Sinodes se voorstelling van die stand van die belydenis in die G.K.N.}

Met betrekking tot die besware en versoeke hierbo vermeld, het die Sinode van Sneek o.a. besluit: „Mede gelet op de discussie herinnert de Synode er aan dat de drie formulieren van enigheid als akkoord van kerkelijke gemeenschap uiteraard bindende gesag hebben" (Acta Sneek, p. 141). Daar word herhaaldelik deur al drie sinodes beklemtoon dat verwag word dat alle ampsdraers hulle ooreenkomstig hulle onderneming, deur die ondertekeningsformulier aangegaan, moet gedra en niks teen die belydenis in die openbaar moet leer nie.

Voorts word verklaar dat Kuitert se opvatting oor die historisiteit van die sondeval teen die besluit van Amsterdam is wat inhou die handhawing van die belydenis (Heid. Kategismus en N.G.B.) op die punte.

Oor die versoeningsleer van Wiersinga besluit die Sinode van Dordrecht dat die leer soos deur die kerk van alle eeue bely gehandhaaf word. Wiersinga - so asof hy'n gravamen ingedien het, wat nie die geval is nie - het geen bewyse aangebring dat die ver- 
soeningsleer, soos uiteengesit in die Belydenisskrifte, strydig met die Heilige Skrif is nie (vgl. Acta Dordt., p. 308). Haarlem 1973 gaan in Junie 1974 verder en verklaar dat die leer van Wiersinga oor die versoening van die belydenisskrifte afwyk en dat hulle (die Sinode) bly by die belydenis van die kerk ten aansien van die plaasbekledende versoeningswerk van Christus, „ook als het dragen van het gericht van God" (vgl. Nederlands Dagblad, 10 Junia 1974). Die Sinode wil dus belydenisgetrou bly.

Hierdie besluite - aangevul deur altyd terugkerende frases uit die mond van die praeses met die strekking van: ,in gehoorzaamheid aan den Heer hebben wij besloten" - weerspreek, wat die sigwaarde daarvan betref, die konklusie wat onder punt 1 getrek is, naamlik dat die belydenis en die gesag daarvan in die krisis is. Ons het hier tog te doen met klinkklare uitsprake ter handhawing van die belydenis wat vas is!

\section{Beoordeling van die voorstelling deur die Sinode}

'n Nadere ondersoek na die besluite in verband met optredes en besluite wat by bg. gevoeg moet word laat egter 'n ander beeld ontplooi.

3.1. Die eerste wat opval is dat met groot erns by konstituering van elke Sinode van elke lid nog die instemming met die drie formuliere van enigheid gevra is. Dit is nie vreemd vir Sinodes wat uitdruklik prys stel op die handhawing van die belydenis nie.

Wat vreemd is, is dat die valse instemming daarmee van persone soos Kuitert, Rothuizen, Augustijn en Wiersinga geduld word: Die persone het vir dekades reeds openlik teen die belydenis te velde getrek en dit op verskeie punte bestry. Daar is weinig artikels van die N.G.B. waarmee genoemde here dit nog volledig eens is. Dink maar oor artt. 3 en 5 insake die Skrif. Die Bybel sê Kuitert, en die res, is die neerslag van die skrywers se ervaring met die Bondgenoot God, dus so tyds- en omstandigheidsgebonde dai ons verplig is om vas te stel wat daarin eintlik die ware openbaring van God is. Ons het in die Bybel te doen met die skrywers se opvattinge. Rustig sê hulle daarom: Ons weet vandag beter as Paulus as dit bv. op etiese sake aankom. Op Art. 12, 13 en 14, oor die Skepping, Voorsienigheid en sondeval, hou elkeen sy eie beskouings na, wat in elk geval nie met die oorspronklike ooreenkom nie. Dieselfde kan gesê word van Art. 16 oor die uitverkiesing en art. 21 tot 23 oor die voldoening van Christus en Regverdigmaking. Ten spyte van die feit dat elkeen weet dat dit so is dat die persone dit nie eens met die belydenis is op die punte nie - sowel deur die inhoud van hulle geskrifte as uitdruklike uitsprake ter sinode - aanvaar die sinode tog hulle valse, ek wil beweer opsetlike valse instemming, waaruit niks anders as minagting blyk nie, met die belydenis !

So 'n optrede weerspreek tog die plegtige versekering dat die Sinode belydenisgebonde is en bly. Indien hierdie optrede nie bewys is van die uiterste oppervlakkigheid en selfs minagting insake wat as fundamenteel vir die bestaan van die kerk geld nie, is dit 
ten minste 'n bewys van totale magteloosheid gebore uit die onsekerheid oor die inhoud sowel as die gesag van die belydenis soos vervat in die drie formuliere van enigheid.

3.2. Die laaste konklusie word versterk deur wat die sinode uitspreek direk na die herinnering aan die bindende gesag van die Formuliere. Dit is naamlik gewens en noodsaaklik: 1) om die vraag onder oë te sien „of en zo ja; hoe de kerk tot een nieuwe belijdenis zou kunnen komen op een voor onze tijd duidelijke wijze en een voor onze tijd duidelijke taal"; 2) dat bedenkinge teen die wyse van inkleding of betoogtrant van die drie Formuliere nog geen beswaar hoef te wees om volledige instemming daarmee te betuig nie.

3.3. Voorts is besluit om na te gaan of daar ,nog andere factoren zijn die in de weg staan van het vragen van een volledige instemming met deze belijdenisschriften". Daarmee is dus implisiet erken dat die sinode vermoed - 'n vermoede wat toe al oor en oor bevestig is - dat daar by ampsdraers nie net bedenkinge teen formele aspekte is soos voorgegee word nie maar ook teen die inhoud van die drie Formuliere.

Die ondersoek word vooruitgeloop - seker nie beredeneerd opsetlik nie, maar noodwendig omdat die diepe oortuiging al moes bestaan het dat daar geen eenheid rondom die drie Formuliere meer moontlik is nie - deur 'n opdrag om die vraag onder oë te sien „of en zo ja; hoe de kerk tot een nieuwe belijdenis zou kunnen komen op een voor onze tijd duidelijke wijze en in een voor onze tijd duidelijke taal". Intussen weer die selfbedrog in die vrome verwagting ,dat alle ambtsdragers zich in het licht van het bovenstaande zullen gedragen naar het geen bepaald is in de ondertekeningsformuliere (Acta Sneek, p. 141).

3.4. Dit is asof die Sinodes, deur 'n onsigbare hand gedwing, besig is met ' $n$ fyne spel om enersyds met groot gebaar die duidelike inhoud en bindende karakter van die belydenis opnuut te proklameer en te handhaaf, en andersyds met alle mag te sorg dat die wat die belydenis verwerp en met die gesag daarvan spot, tog genoeg ruimte in die G.K.N. sal hê. Die stelling vind grond daarin dat op die Sinode van Dordrecht 1971/72 daar "genuanceerd" bevestigend geantwoord is dat daar meer besware is teen die belydenisskrifte as teen die inkleding en betoogtrant. Die feit word so aanvaar, sonder om die noodwendige konklusie te trek dat die ,akkoord van kerklike gemeenskap" daarmee opgehef is nie! Rustig word voortgegaan om die probleem te oorbrug deur die opdrag om 'n nuwe ondertekeningsformulier op te stel waarin - soos verwag kan word - die gebondenheid aan Skrif en belydenis beklemtoon word, maar waarin tog ruimte genoeg gelaat word vir beswaardes. Wie besware het teen die leer moet ,uit die drang der broederlijke liefde bij de kerkelijke vergaderinge getuigenis afleggen" en hulle aan die kerklike oordeel onderwerp. Daar word egter nie gesê wat sal gebeur as hulle die drang nie het nie! Daar is probeer om die skyn dat leervryheid nie ingevoer is nie in elk geval deur die nuwe formulier te handhaaf (vgl. acta Dordt., p. 260). 
3.5. Ten aansien van die vraag na 'n nuwe belydenis spreek Dordt uit dat dit van groot belang is om te probeer om tot 'n "eenparige geloofsgetuigenis te komen" in 'n duidelike taal en in verband met die vrae van hierdie tyd, as 'n moontlike weg tot 'n nuwe belydenis "in gemeenschap des geloofs met het belijden der vaderen" ( $p p$. 170/1).

Opmerklik dat hier die presiese terminologie van die Hervormde Kerk tydens die Afscheiding en Doleansie, stilweg oorgeneem word om die toekomstige band aan die drie Formuliere van enigheid te tipeer as histories van aard.

Aan professore Berkouwer en Ridderbos is opgedra om 'n „proeve" van so 'n eenparige geloofsgetuienis op te stel. Toe hulle die ,proeve" gedurende Januarie 1974 aan die Sinode van Haarlem voorlê praat die deputate in hulle verantwoording oor hulle opdrag van die vraag na die geloofsgetujenis ,in en ondanks alle verschillen die onder ons niet te loochenen zijn ..." As agtergrond en motiewe vir die opdrag geld o.a. die feit dat daar in die G.K.N. die laaste jare 'n strewe is ,naar het verstaan van het wezenlijke, centrale en fundamentele van het belijden".

Ten spyte dus van die herhaalde troubetuiging aan die belydenis soos vervat in die Drie Formuliere van Enigheid, word nou by monde van Berkouwer en Ridderbos onomwonde verklaar - hoewel in 'n sagte vorm - dat die belydenisskrifte nie meer deug nie omdat daar nie meer instemming mee is nie. Daaraan voeg hulle nog die „nieuwe situasie" toe dat „vragen van deze tijd" nie beantwoord word in die ou konfessies nie "omdat ze buiten de horizon van die tijd leggen" (vgl. geloofsgetuigenis 1974, pp. 11 en 12).

Die „proeve" van so 'n getuigenis wat die weg moet baan vir die altyd-nodiger-nuwe belydenis, omvat ' $n$ inleidende deel ter verklaring van wat onder geloof, Openbaring, die Heilige Skrif en die "Mens Gods" verstaan moet word (pp. 17-20). Dan volg 10 Artikels (t.o. die 32 van die N.G.B.) waarin die ,inhoud van ons algemeen christelijk geloof" wat ons bely saamgevat is. Die artikels handel oor:

1. God onze vader.

2. God en mens.

3. Jesus Christus, Gods zoon, onze Heer.

4. Rechtvaardiging en verzoening.

5. Het Rijk van Christus.

6. De kerk.

7. Doop en avondmaal.

8. De Heilige Geest.

9. Kerk en wereld.

10. De toekomst des Heren.

Die tyd ontbreek om ' $n$ indringende analise en beoordeling van die Proeve te gee. Ek volstaan met aan te toon dat in die lig van die opdrag die Proeve, ten spyte van die entoesiastiese aanvaarding daarvan op die Januarie 1974 sitting van die Sinode Haarlem, 'n geweldige teleurstelling is juis t.a.v. die twee vereistes wat daaraan gestel is naamlik die verstaan van die "wezenlijke, centrale en fundamentele inhoud" en dat daarin ,alle verwarring, onduidelijk- 
heid en tegenspraak moeten zijn uitgesloten" t.o.v. die ene en enige „boodschap des heils", en die antwoorde op die „vragen van dezen tijd".

Uit die opsomming van die inhoud van die 10 artikels hierbo is dit reeds duidelik dat indien dit die weergawe is van die wesenlike, sentrale en fundamentele inhoud van die belydenis, is die Proeve 'n baie duidelike reduksie of inkorting van die bestaande belydenis. Artikels onder andere oor die Drie-eenheid, Heilige Skrif, Voorsienigheid, Verkiesing en Verwerping, die Laaste Oordeel; is bloot weggelaat. Die vraag is nou of die belydenis hiervan nie meer van wesenlike betekenis is vir die G.K.N. nie.

Dit val op dat juis oor meeste van die punte daar verskil is in die G.K.N. en dat met die reduksie doelbewus instemming van alle partye in die G.K.N. gesoek is.

Wat betref die ,vragen van dezen tijd", kan met die beste wil ter wêreld in die Proeve geen enkele antwoord op 'n vraag wat die G.K.N. vandag beroer eksplisiet gevind word nie. Wat oor die Skrifgesag, byna terloops, en die versoening of opstanding van Christus of sy wederkoms bely word is so geformuleer dat regs, midderegs en links almal daarmee kan instem!

In die artikels kom 'n poging om die nuwe teoloë soos Kuitert in die gevlei te kom na vore selfs in uitdrukkinge en sinswendinge. Daar word gepraat van die mens as bondgenoot van God op aarde. Daarmee word, hoewel die verbondsgedagte nie in die betrokke artikel 2 op die voorgrond is nie, tog 'n ander inhoud aan die verbond gegee. Voorts word die name Adam en Eva krampagtig vermy, van die Paradys nie gespreek nie en die sondeval is toe te skryf aan 'n vreemde verleiding ,waarvoor die mens beswyk het". Nêrens word die Satan of selfs die engele by name genoem nie. In artikel 10 is Christus ook nie die tweede Adam soos volgens die Skrif nie, maar wel die "tweede mens".

Die mens het nie in die mag van Satan gekom nie, „maar onder die bekoring van het kwaad" art. 2).

Oor die "Rechtvaardiging en verzoening" is daar geen poging om Wiersinga se dwaalleer uit en af te wys nie (soos bedoel was met die Proeve). Nêrens word eers eksplisiet benadruk dat Christus moes ly of dat Hy die toorn van God moes dra nie. Al wat in art. 4 gebeur is dat die N.G.B. en Kategismus op die punt so verswak is dat ook Wiersinga se simpatiseerders ter sinode met die formulering kon instem. Die opvatting van Wiersinga dat die versoening eintlik opgaan in die versoening van die medemens word in soverre "gehonoreer" dat 2 volle paragrawe daaraan gewy word (art. 4 w). Ek meen hiermee genoegsaam aanduidings te gegee het om $u$ te laat begryp dat die "Proeve" eintlik bedoel om die belydenis so te reduseer dat die leerverskille in die G.K.N. onbelemmerd kan voortwoeker sonder die keuse tussen waarheid en leuen en dat die sg. eietydse vrae oor die Skrifinspirasie, opstanding, wederkoms, aard van die koninkryk van die hemele, ens. rustig in die midde gelaat word.

3.6. Die voorstelling van belydenistrou gètoets aan die optrede teen die wat afwyk van die belydenis. 
Om die voorstelling van die Sinodes van die G.K.N. dat die Belydenis nog as akkoord van kerklike gemeenskap bindende krag het verder te toets wys ek $u$ net op die gebrek aan optrede teen 'n groot aantal professore en predikante wat voortgaan om openlik in preke, toesprake en geskrifte voort te gaan om afwykende beskouinge te propageer en om die belydenisskrifte as verouderd te verklaar. Om die kroon te span word volgens die verklaring van 'n student geduld dat te Kampen 'n vereniging van Marxiste onder die Teologiese studente openlik bestaan. Hulle probeer om Marxistiese doelstellings in die Teologiese Skool te verwensenlik. Hulle wil die struktuur van die Teologiese Skool verander. „Er kome dan dominees van een ander soort ... De bijbel zal het dan niet meer uitsluitend voor het zeggen hebben, maar de uitleg van de ,bijbelse noties' volgens de marxistische levensbeschouwing zal de heilstaat op aarcle dichterbij brengen" (Friesch Dagblad, 31 Mei 1974).

Die student, dr. Spoelstra, wat die dinge openbaar beweer dat die groep nie 'n onwettige posisie inneem te Kampen nie. Hulle word 'n plek gegun nie net deur hulle medestudente nie, maar ook deur die professore wat ,de onderwerpen van hul colleges en de te bestuderen stof niet zelden aanpassen aan de smaak van de studenten" (vgl. idem). So moes die studente vir prof. Runia 'n preek of preekskets maak oor Lukas 5:1-11. Die Marxiste weier toe omdat ,wij het onmogelijk achten daar een preek in de alhicr gebruikelijke (en dus verwachte) zin over te maken, daar dit maatschappelijk en dus ook Theologies niet te rechtvaardigen zou zijn (kursivering van my). Wij zien dus theologiese arbeid allereerst als maatschappelijke arbeid en wensen dit expliciet te verdisconteren" (idem).

Die Kuratorium verklaar wel dat vir die Marxisme aan die teologiese skool geen plek is nie, maar neem dr. Spoelstra kwalik dat hy publisiteit aan die saak gegee het en toon aan dat die studentebond nie erken word nie terwyl die studente buitendien hulleself nie aangedui wil sien as ,aanhangers van het leninistisch-marxisme, al menen zij, dat van daaruit vragen kunnen worden gesteld over de wijze, waarop de theologie wordt beofend" (Nederlands Dagblad, 15 Junie 1974).

Hier dus weer die tipies magtelose optrede! Die verontruste dr. Spoelstra doen 'n onreg om op die kwaad te wys en dit is buitendien nie so erg nie, hulle word nie offisieel erken nie en hulle bedoel dit goed en kan derhalwe voortgaan!

3.7. Dit stem ooreen met die optrede teen Kuitert en Wiersinga. Hoewel gekonstateer is dat Kuitert se leer nie ooreenstem met die belydenis nie (Sneek en Dordrecht) word die „diskussie” met hom beëindig omdat sy afwyking nie die geloofseenheid bedreig nie en hy verklaar dat hy die drie formuliere van enigheid aanvaar - ten spyte van alles wat die teendeel bewys!

3.8. Net so naief is die antwoord wat die Sinode Dordrecht gee op die eis dat gesorg moet word dat Kuitert e.a. aan die V.U. in die opleiding gebonde moet bly aan die belydenis. Die Sinode „oorweeg" dat die bestaande reëling met die V.U. „biedt voldoende waarborgen, dat die opleiding van onze a.s. predikanten gegee wordt 
vanuit de aanvaarding van de belijdenis onzer kerk" (acta Dordrecht, p. 169, art. 194). Dit ten spyte van die openlike en toenemende minagting van die belydenis wat aan die V.U. in die onderrig van die studente geopenbaar word deur Kuitert, Augustijn en andere, asook aan die Teologiese Skool te Kampen deur o.a. Baarda, Rothuizen, e.a.

3.9. Eindelik het Haarlem 1973 op sy sitting van Junie 1974 besluit dat teen Wiersinga nie opgetree word nie en dat hy nie in sy ampswerk gesteur moet word nie omdat, hoewel sy versoeningsleer afwyk van die belydenis, deur tog nog 'n innige geloofsgemeenskap tussen hom en die sinode is (vgl. rapport van deputate). Hy word gevra om te luister na die oordeel van die Sinode dat sy beskouing afwykend is en versoek of hy hom nie sal besin „op de vraag of zijn ... leer over de verzoening geen herziening behoeft" (Nederlands Dagblad, 10 Junie 1974). Ten slotte is bygevoeg dat die Sinode verway dat hy in sy werk as predikant die belydenis nie sal weerspreek nie - ten spyte van die feit dat hy persoonlik nadruklik op die Maartsitting verklaar het dat hy sy werk alleen kan voortsit deur sy eie versoeningsleer aan die studente voor te hou.

\section{Slot}

Dit het reeds 'n lang verhaal geword terwyl daar nog soveel materiaal oorbly net vir die gryp om te verwerk! Dink aan besluite oor die amp; die ekumene; ,samen-op-weg": die verbroedering met die Hervormde Kerk; die gesamentlike dienste met Roomse; die Liturgiek; etiek 0.a. rakende sodomie. Daarby kom nog die jongste boek van Kuitert: „Zonder geloof vaart niemand wel”, waarin hy in feite afskeid neem van die Christendom.

Uit wat behandel is, is dit egter baie duidelik dat die belydenis soos vervat in die Drie Formuliere van Enigheid in die G.K.N. tans ten spyte van ontkennings, net historiese waarde het as die „belijden der vaderen". Ten spyte van 'n vertoon van belydenishandhawing het hulle dit laat vaar as akkoord van kerklike gemeenskap en berus die kerkverband vir hulle tans op beginsels soos van tyd tot tyd op ooreenkom.

Die vraag is dus die afgelope tyd gestel of die Geref. Kerk in S.A. nou die bande met die G.K.N. moet verbreek of nie. Die vraag gaan egter uit van 'n valse siening van die verhouding tussen die kerke. Solank die belydenis, vervat in die Drie Formuliere as akkoord van kerklike gemeenskap gehandhaaf word is daar vanselfsprekend eenheid tussen die kerke. Maar net so vanselfsprekend is die eenheid opgehef sodra een of albei kerke die akkoord prysgee. Dit is dus, gesien die huidige stand van die belydenis in die G.K.N. nie meer ' $n$ vraag of daar gebreek moet word nie; die feit is dat die G.K.N. die band reeds de facto verbreek het met die prysgawe van die belydenis soos vervat in die Drie Formuliere as die akkoord van gemeenskap. Die sinode van die G.K.S.A. moet nog slegs in 1976 D.V. formeel konstateer dat dit die geval is.

- G. P. L. van der Linde.

(Gelewer voor G.T.V. van die O.V.S. te Welkom op 3 Sept. 1974) 